\title{
Impact of knee osteoarthritis on muscle force, function and quality of life
}

\begin{abstract}
Introduction: isokinetics is a reference method for evaluation of muscle strength. It enables a functional diagnosis by specifying levels of disability and performance deficits in the subject with knee osteoarthritis.

Objective: To determine the isokinetic profile in the subject with knee osteoarthritis compared to a healthy population

Materials and methods: A 6-month prospective, descriptive, and analytical cohort study on 30 patients with knee osteoarthritis by comparison with 15 healthy subjects, collected in the Department of Physical Medecine and Rehabilitation of Ibn Rochd University Hospital, Casablanca, Morocco. The two groups received a clinical and parclinical evaluation as well as an isokinetic evaluation

Results: The average age was $42.53+/-11.41$ years with female predominance $(80 \%)$. The isokinetic evaluation noted a significant difference in the maximum torque peak (MTP) of the quadriceps (Q) and the hamstrings between the e 2 evaluated groups, a significant difference in work and in the $\mathrm{Q}$ and $\mathrm{H}$ power between the 2 groups. We found, in addition, no significant difference In the $\mathrm{Q}$ and $\mathrm{H}$ tiredness index as well as the $\mathrm{Q} / \mathrm{H}$ ratio between the 2 assessed groups.

Discussion/conclusion: Knee osteoarthritis is associated with pain and limitation of functional capacity but Also with muscle weakness which in itself affects the evolution of the disease hence the importance of quadriceps and hamstrings reinforcement in the increase of muscle strength, stability and joint mobility for the purpose of obtaining better pain tolerance and therefore a better quality of life.
\end{abstract}

Keywords: knee osteorthritis, isokinetism, muscle strength, quality of life
Volume 2 Issue 2 - 2017

\section{Laila Mahir, Siham Zahi,Yvette Moigny, Fatima Lmidmani, Abdellatif El Fatimi}

Department of Physical medicine and rehabilitation, Morocco

Correspondence: Laila Mahir, Physical medicine and rehabilitation department, Morocco,

Emailmahirlaila@hotmail.com

Received: June 20, 2017 | Published: November 20, 2017

\section{Introduction}

Knee osteoarthritis is the most frequent localization of osteoarthritis, and the incidence of its symptomatic form is estimated at $240 / 100000$ persons per year. ${ }^{1}$ Furthermore, we estimate that more than $80 \%$ of people aged over 55 undergo knee radiological modifications related to osteoarthritis, even outside all symptomalogy. ${ }^{2}$ International recommendations show the benefit of physical exercise and in particular that of muscular reinforcement and of personalized physical exercise in the therapeutic care of osteoarthritis. ${ }^{3,4}$ It improves functional capacities such as walking and other daily activities and reduces pain.

Isokinetism allows a functional diagnosis by specifying the degree of incapacity and performance deficiencies. The analysis of collected data enables us to personalize rehabilitative treatment by locating specifically the sectors in which muscular reinforcement must be done. ${ }^{5}$ The objective of this study is to evaluate the isokinetic muscular benefit to the patient with knee osteoarthritis in comparison with a group of patients who are healthy and free of any pathology at the level of the knee, as welle as to evaluate the impact of knee osteoarthritis on the functioning and the quality of life of our patients.

\section{Material and methods}

\section{General description of the study}

It is a prospective, descriptive and analytical cohort study that lasted 6 months, and undertaken on 30 patients with knee osteoarthritis in comparison with 15 healthy subjects from the general population, collected at the Department of Physical Medicine and Rehabilitation of Ibn Rochd University Hospital, in Casablanca.

\section{Inclusion criteria}

As for the group of patients, the ones included in the study were patients with a clinical bilateral knee osteoarthritis, and confirmed by radiology. As for the control group, the ones included were subjects who are free of any pathology relative to the lower limbs.

\section{Exclusion criteria}

The ones who were excluded from the study were patients with a contraindication to isokinetism or presenting a severe pain or having a unilateral knee osteoarthritis, as well as patients with an advanced level of knee osteoarthritis (the Kellgren and Lawrence (KL) classification). ${ }^{6}$

\section{Clinical evaluation}

The questionnaire enabled us to collect sociodemographic data, antecedents, and functional signs. A programmed clinical examination of knees of all evaluated subjects was carried out. The paraclinical checkup included standard knee radiographies, allowing a radiological Kellgren and Lawrence classification of the knee osteoarthritis.

\section{The scales of evaluation}

We administered various scales of evaluations to our patients; thus, 
pain was evaluated by visual analog scale (VAS pain). The function was evaluated by WOMAC questionnaire ${ }^{7}$ and Lesquene Index $^{8}$ and the quality of life by MOS SF36. ${ }^{9,10}$

\section{Isokinetic evaluation}

An isokinetic dynamometer, whose brand name is CYBER HUMAC was used. The isokinetic evaluation was preceded by a 15-minute warm up on an ergocycle and a pre-test to familiarize our patients with the handling of the machine.Medical care was provided to patients with pain before they went through the isokinetic test, for the results of the evaluation not to be biaised by the pain factor (patients can get more involved in the isokinetic evaluation). Participants were seated properly by a physical therapist on the CYBEX dynamometer and leaned against a backrest inclined at $16^{\circ}$ from vertical and with the seat inclined $6^{\circ}$ from horizontal. The axis of the dynamometer was aligned with the flexion-extension axis of the knee. The trunk, waist, distal thigh and leg were secured with straps to stabilize the body and minimize muscle compensation. All measurements incorporated a gravity-correction procedure. During the test, testers gave verbal feedback as needed to maintain proper positioning. We realised two series of evaluation in a concentric mode: 5 repetitions at $60 \%$ and 15 repetitions at $180^{\circ} / \mathrm{s}$.

We have analyzed the following parameters in both groups:

i. Maximum peak torque (MPT) of the quadriceps and the hamstrings.

ii. H/Q Ratio. iii. Work, strength, and index of tiredness of knee extensors and flexors.

\section{Statistical analysis}

Data was analyzed with the use of SPSS 20.0. Software. The Shapiro-Wilk normality test was carried out for all variables. Patients demographic characteristics were described by means and standard deviations. The comparison between the dominant and the non-dominant side was evaluated by the Wilcoxon Test, whereas the comparison between the two groups of subjects with knee osteoarthritis and the healthy ones was done by the Mann-Withney Test. The results are considered significant for $\mathrm{p}<0,05$.

\section{Results}

\section{Sociodemographic characteristics}

Our study involves 30 patients with bilateral knee osteoarthritis, aged in average 42.53 years $+/-11.41$. We noted a female predominance $(80 \%) .83 .3 \%$ of patients were sedentary, and the remaining $16.7 \%$ were amateur sportsmen and women. Subjects in both groups are compatible as far as sociodemographic characteristics are concerned: age, weight, height, and body Mass Index (Table 1). They are also compatible in regards to daily activity and laterality (Table 2). The control group involved 15 subjects, whose average age was 38.13 years \pm 8.74 , with female predominence of $73 \%$. Among the patients, two had an antecedent of ligamentoplasty; a patient had a meniscectomy;a female patient had an ACL rupture with a nonoperated-on meniscus injury; and the 26 remaining patients had no knee antecedent.]

Table I Sociodemographic characteristics of patients with knee osteoarthritis and of healthy subjects

\begin{tabular}{llll}
\hline Parameters & Patients with knee osteoarthritis & Control group & P \\
\hline Age (years) & 42,53 years $\pm \mid \mathrm{I}, 4 \mathrm{I}$ & 38,13 years $\pm 8,74$ & 0.064 \\
Weight $(\mathrm{Kg})$ & $73,83 \mathrm{Kg} \pm \mid 3,26$ & $72,86 \mathrm{Kg} \pm 1 \mathrm{I}, 35$ & 0.904 \\
Height $(\mathrm{cm})$ & $162,7 \mathrm{~cm} \pm-8.22$ & $17 \mathrm{I}, 66 \mathrm{~cm} \pm-6,32$ & 0.805 \\
BMl $\left(\mathrm{Kg} / \mathrm{m}^{2}\right)$ & $27,99 \mathrm{Kg} / \mathrm{m}^{2} \pm 5,27$ & $24,67 \mathrm{Kg} / \mathrm{m}^{2} \pm 0,57$ & 0.833 \\
\hline
\end{tabular}

Table 2 Descriptive characteristics of patients with knee osteoarthritis and of healthy subjects

\begin{tabular}{llll}
\hline Parameters & & Patients with knee osteoarthritis & Control group \\
\hline Laterality & Right & $90 \%(27)$ & $86,7 \%(13)$ \\
& Left & $10 \%(3)$ & $13,3 \%(2)$ \\
Level of fitness & Sedentary & $83,3 \%(25)$ & $86,7 \%(13)$ \\
& Amateur sportspersons & $16,7 \%(5)$ & $13,3 \%(2)$ \\
\hline
\end{tabular}

\section{Clinical evaluation}

According to the Kellgren and Lawrence Classification, $50 \%$ of patients had Level 3;33.3\% had Level 2; and 16.7\% had Level 1.

\section{Scales of evaluation}

Scales of algo-functional evaluation and of the quality of life were altered for patients with knee osteoarthritis (Table 3).

\section{Isokinetic evaluation}

We did not come up with any significant difference, neither in the BMI of the dominant and non-dominant quadriceps nor in that of dominant and non-dominant of both evaluated groups (Table 6). We did not note any significant difference in H/Q strength ratio of dominant and non-dominant limbs in both groups (Tables 4) (Table 5); on the other hand, the H/Q strength ratio was unbalanced in most 
cases in both groups but without any significant difference from this one between the two evaluated groups (Table 6).

As regards work, we have not noted any significant difference neither in the work of dominant and non-dominant quadriceps nor in that of the dominant and non-dominant hamstrings of both evaluated groups (tables $4 \& 5$ ); on the other hand, we have found a significant difference of both the quadriceps work and the hamstrings between the 2 evaluated groups (Table 6). Regarding strength, we have not noted any significant difference in the strength of dominant and nondominant quadriceps, nor did we in that of the dominant and nondominant hamstrings of both evaluated groups (Tables 4) (Table 5) but the difference between quadriceps and hamstrings strength between the 2 evaluated groups was significant (Table 6).

Table 3 Results of evaluation scales in patients with knee osteoarthritis

\begin{tabular}{lll}
\hline Parameters & Average & Extremes \\
\hline VAS pain & 5 & {$[3-7]$} \\
Lequesne algofunctional score & 9,31 & {$[3-16]$} \\
WOMAC score & 63,63 & {$[50-90]$} \\
SF 36 physical health & 40,63 & {$[20,6-63,9]$} \\
SF 36 mental health & 44,20 & {$[27,9-61]$} \\
\hline
\end{tabular}

Table 4 Results of isokinetic parameters in patients with knee osteoarthritis.

\begin{tabular}{llll}
\hline Parameters & Dominant knee & Non dominant knee & p \\
\hline BMI quadriceps & $95 \mathrm{NM}$ & $92 \mathrm{NM}$ & 0.336 \\
BMI hamstrings & $45 \mathrm{NM}$ & $43 \mathrm{NM}$ & 0.784 \\
H/Q strength ratio & 0.48 & 0.45 & $0.38 \mathrm{I}$ \\
Work quadriceps & $\mathrm{II} 7 \mathrm{~J}$ & $109 \mathrm{~J}$ & 0.094 \\
Work hamstrings & $57 \mathrm{~J}$ & $54 \mathrm{~J}$ & 0.869 \\
Power quadriceps & $64 \mathrm{~W}$ & $62 \mathrm{~W}$ & 0.487 \\
Power hamstrings & $3 \mathrm{IW}$ & $30 \mathrm{~W}$ & 0.964 \\
Index of tiredness quadriceps & 22 & 20 & 0.6 \\
Index of tiredness hamstrings & 23 & 26 & 0.44 \\
\hline
\end{tabular}

Table 5 Results of isokinetic parameters in healthy subjects

\begin{tabular}{llll}
\hline Parameters & Dominant Knee & Non Dominant Knee & p \\
\hline BMI quadriceps & I65NM & I6INM & 0.27 \\
BMI hamstrings & $88 \mathrm{NM}$ & $83 \mathrm{NM}$ & 0.194 \\
H/Q strength ratio & $0.5 \mathrm{I}$ & 0.5 & 0.686 \\
Work quadriceps & $184 \mathrm{~J}$ & $184 \mathrm{~J}$ & $\mathrm{I}$ \\
Work hamstrings & $106 \mathrm{~J}$ & $10 \mathrm{IJ}$ & $0.26 \mathrm{I}$ \\
Power quadriceps & $1 \mathrm{IIW}$ & $109 \mathrm{~W}$ & 0.58 \\
Power hamstrings & $65 \mathrm{~W}$ & $60 \mathrm{~W}$ & 0.83 \\
Index of tiredness quadriceps & 22 & 23 & 0.774 \\
Index of tiredness hamstrings & 29 & 29 & $\mathrm{I}$ \\
\hline
\end{tabular}

Table 6 Comparison between the different isokinetic parameters in patients knee osteoarthritis and healthy subjects

\begin{tabular}{llll}
\hline Parameters & Patients with knee osteoarthritis & Healthy subjets & P \\
\hline BMI quadriceps & $94 \mathrm{NM}$ & I63NM & $0.000 \mathrm{I}$ \\
BMI hamstrings & $44 \mathrm{NM}$ & $85 \mathrm{NM}$ & $0.000 \mathrm{I}$ \\
H/Q strength ratio & 0.47 & $0.5 \mathrm{I}$ & 0.229 \\
Work quadriceps & $\mathrm{II} 3 \mathrm{~J}$ & $\mathrm{I} 84 \mathrm{~J}$ & $0.000 \mathrm{I}$ \\
Work hamstrings & $55 \mathrm{~J}$ & $103 \mathrm{~J}$ & $0.000 \mathrm{I}$ \\
Power quadriceps & $63 \mathrm{~W}$ & $\mathrm{II} 0 \mathrm{~W}$ & $0.000 \mathrm{I}$ \\
Power hamstrings & $3 \mathrm{IW}$ & $63 \mathrm{~W}$ & $0.000 \mathrm{I}$ \\
Index of tiredness quadriceps & $2 \mathrm{I}$ & 23 & 0.333 \\
Index of tiredness quadriceps & 24 & 29 & 0.12 \\
\hline
\end{tabular}


Finally, concerning the index of tiredness or ratio, no significant difference of tiredness index at the level of dominant and nondominant quadriceps or that of the dominant and non-dominant hamstrings in both evaluated groups (Tables $4 \& 5$ ). Similarly, no evidence whatsoever of any significant difference in quadriceps and hamstrings tiredness was noted between the 2 evaluated groups (Table $6)$.

\section{Discussion}

Although knee osteoarthritis is defined and diagnosed as a loss of hyaline cartilage at the level of articulation, muscular impairment associated with this pathology, especially that of the quadriceps, can be the main underlying cause of the observed functional alterations. ${ }^{11,12}$ and can even precede or accelerate cartilage deterioration. ${ }^{13,14}$ Studies have demonstrated a significant correlation between functional impairment and the decrease in muscle strength, ${ }^{15,16}$ the latter being observed in patients in relation to control patients in both groups of patients, that is, the one with osteoarthritis and the healthy one. ${ }^{17}$ Furthermore, the patients with a more significant impairment in the side affected by osteoarthritis by comparison with the healthy side in isometric contraction as well as in concentric contraction..$^{18,19}$ Diraçoglu et al. ${ }^{20}$ Consider that muscular weakness in lower limbs is one of the most important causes of locomotor dysfunction and invalidity in patients suffering from knee osteoarthritis. In a comparative study involving 51 patients with knee osteoarthritis and 43 healthy subjects, the manual muscle testing of the quadriceps was, for the knee osteoarthritis affected patients, of $4 / 5$ for 6 knees and of $5 / 5$ for 96 knees, whereas in the control group only 2 legs were rated at $4 / 5$ and 84 knees had a muscular strength rated at $5 / 5(p=0.22)$. As regards quadriceps isokinetic tests, there was a difference between the 2 groups of $20 \%$ for the concentric isokinetic tests at $60 \%$ s, of $19 \%$ for the concentric isokinetic tests at $180 \%$ and of $11 \%$ for concentric isokinetic tests at a velocity of $240 \%$ s. For the hamstrings, the study found a difference in muscle strength of $29 \%$ for the concentric isokinetic tests at $60 \%$, of $15 \%$ for the concentric isokinetic tests at $180 \%$ s and of $18 \%$ for tests at $240 \%$ s.

Tan et al. ${ }^{21}$ in a comparative study between 30 patients displaying clinical and radiological signs of knee osteoarthritis and 30 healthy subjects, find a quadriceps strength difference of $27 \%$ for the concentric isokinetic tests at $60 \%$ and of $23 \%$ for the concentric isokinetic tests at $180^{\circ} \mathrm{s}$. For the hamstrings muscles the difference was of $29 \%$ for the concentric isokinetic tests at $60 \%$ and of $28 \%$ concentric isokinetic tests at $180^{\circ} \mathrm{s}$.

Slemenda et al. ${ }^{22}$ studying the difference in muscle force between healthy subjects and patients with knee osteoarthritis, found a difference of $16 \%$ of concentric isokinetic strength at a velocity of $60 \%$ for the quadriceps muscle and of $7 \%$ for the hamstrings muscle. They have also noted that the quadriceps weakness can be a more precocious sign of pain or muscle atrophy throughout knee osteoarthritis. This suggests that the weakness may be due to a muscle dysfunction. This data is compatible with the possibility that quadriceps weakness may be a risk factor for gonalgia, handicap, and the progression of joint injuries in people with knee osteoarthritis. For Hortobagyi et al. ${ }^{23}$ quadriceps weakness is a characteristic symptom of knee osteoarthritis. Compared with healthy subjects, patients with knee osteoarthritis present an impairment in the muscle strength of the quadriceps ranging from $10 \%$ à $60 \%$.

Muscle weakness of the quadriceps is normally quantifiable by a reduction of isokinetic and isometric maximum concentric muscle strength. ${ }^{24}$ However, daily life activities also involve eccentric contractions. In this respect, Hortobagy et al conducted a comparative study between two groups (a group of 20 subjects with knee osteoarthritis and a control group made up of 20 healthy subjects of the same age and sex). Patients affected by knee osteoarthritis produced $76 \%$ less eccentric isokinetic strength and $56 \%$ less isometric concentric isokinetic strength. The eccentric strength of patients with knee osteoarthritis $20 \%$ was better compared to their concentric strength. Overall, patients with knee osteoarthritis produced $63 \%$ less quadriceps strength by comparison with the control group $(\mathrm{p}<0,05)$.

In general, concentric isokinetic tests in patients with knee osteoarthritis are subject to a strength impairment ranging from 11 to $54 \%$ for the quadriceps muscle and ranging from 7 to $38 \%$ for hamstrings muscle by comparison with healthy subjects. Differences in the intensity of strength impairment obtained in these studies may be attributed partially to differences in subjects' characteristics, the severity of the knee osteoarthritis, and the definition of the control group. In our study, the strength impairment is of $42,5 \%$ for the quadriceps muscle, which concurs with the literature data.

Anita Emrani et al. ${ }^{17}$ studied the difference in peak torque between a control group consisting of 20 healthy subjects and a group consisting of 20 patients with knee osteoarthritis. There was a significant difference in the peak torque between the two studied groups in both angular velocities $(\mathrm{p}<0.00)$.

Elsadat et al. ${ }^{25}$ carried out a comparative study amongst 4 groups of subjects: 1 group of healthy subjects and 3 groups of subjects with knee osteoarthritis (group I:mild knee pain; group II:moderate knee pain; group III:severe knee pain).

For the mode of concentric contraction at the velocity of $40 \%$, the peak torque value of the healthy group was significantly higher than the other groups $(p=0.000)$. The peak torque value of group I was significantly higher than those of groups II et III $(\mathrm{p}=0.000)$ and the peak torque value of group II was significantly higher than that of group $\operatorname{III}(\mathrm{p}=0.000)$. For the mode of concentric contraction at the angular velocity of $120 \%$ s, there was no significant difference between the peak torque value of the group of healthy subjects and of group $\mathrm{I}(\mathrm{p}=0.333)$. Yet, the peak torque of the group of healthy subjects was significantly higher than those of groups II and III $(\mathrm{p}=0.000)$. Moreover, the peak torque of group I was significantly higher that those of group II and III $(\mathrm{p}=0.000)$, and the peak torque of groupe II was significantly higher than that of group $\operatorname{III}(p=0.000)$.In our study, we found a significant difference in the peak torque of quadriceps and hamstrings muscles in both evaluated groups $(\mathrm{p}=0.0001)$.

\section{Conclusion}

Several studies showed interest in determining the profiles of muscle strength by isokinetism throughout knee osteoarthritis. Indeed, these studies objectified a decrease in the muscular strength of knee extensors and flexors, which explains the implication of muscular change in the handicap and incapacity of patients with knee osteoarthritis, outside problems linked with articulation itself.

Apart from the important role it plays in the evaluation of muscular strength ${ }^{26}$ isokinetism is equally a method that has its place in muscle reinforcement ${ }^{27,28}$ and may, probably, inscribe itself in the therapeutic arsenal of knee osteoarthritis in addition to other treatments.

\section{Acknowledgements}

None. 


\section{Conflict of interest}

The author declares no conflict of interest.

\section{References}

1. Oliveria SA, Felson DT, Reed JI, et al. Incidence of symptomatic hand, hip, and knee osteoarthritis among patients in a health maintenance organization. Arthritis Rheum. 1995;38(8):1134-1141.

2. Rosa UH, Velásquez TJ, Lara MC, et al. Comparison of the effectiveness of isokinetic vs isometric therapeutic exercise in patients with osteoarthritis of knee. Reumatol Clin. 2012;8(1):10-14.

3. Jordan KM, Arden NK, Doherty M, et al. EULAR Recommendations 2003: an evidence based approach to the management of knee osteoarthritis: Report of a task force of the standing committee for international clinical studies including therapeutic trials (ESCISIT). Ann Rheum Dis. 2003;62(12):1145-1155.

4. Jegu AG, Pereira B, Andant N, et al. Effect of eccentric isokinetic strengthening in the rehabilitation of patients with knee osteoarthritis : Isogo, a randomized trial. Trials. 2014;15:15-106.

5. E Coudeyre, J Marrel, D Claus, et al. Intérêt et place du renforcement musculaire isocinétique dans le traitement de la gonarthrose. Lett Med Phys. 2011;27:33-40.

6. Christian C, Emmanuel M. Evaluation radiographique de l'arthrose: critères et indices. Revue du rhumatisme. 2010;77(2):135-143.

7. Bellamy N. The WOMAC knee and hip osteoarthritis indices: development, validation, globalization and influence on the development of the AUSCAN hand osteoarthritis indices. Clin Exp Rheumatol. 2005;23(5 Suppl 39):S148-153.

8. Faucher M1, Poiraudeau S, Lefevre CMM, et al. Assessment of the testretest reliability and construct validity of a modified lequesne index in knee osteoarthritis. Joint Bone Spine. 2004;71(6):121-127.

9. Ware JE, Gandek B. Overview of the SF-36 health survey and the international quality of life assessment (IQOLA) project. J Clin Epidemiol. 1998;51(11):903-912.

10. Ware JE, Gandek B, Kosinski M, et al. The equivalence of SF-36 summary health scores estimated using standard and countryspecific algorithms in 10 countries: results from the IQOLA Project. International quality of life assessment. J Clin Epidemiol. 1998;51(11):1167-1170.

11. Hurley MV, Scott DL, Rees J, et al. Sensoriomotor changes and functional performance in patients with knee osteoarthritis. Ann Rheum Dis. 1997;56(11):641-648.

12. O'Reilly SC, Jones A, Muir KR, et al. Quadriceps weakness in knee osteoarthritis: the effect on pain and disability. Ann Rheum Dis. 1998;57(10):588-594.

13. Bennell KL, Hunt MA, Wrigley TV, et al. Role of muscle in the genesis and management of knee osteoarthritis. Rheum Dis Clin North Am. 2008;34(3):731-754.
14. Alnahdi AH, Zeni JA, Snyder ML. Muscle impairments in patients with knee osteoarthritis. Sports Physical Therapy. 2012;4(4):284-292.

15. Gur H, Cakun N. Muscle mass: isokinetic torque and functional capacity in women with osteoarthritis of the knee. Arch Phys Med Rehabil. 2003;84(10):1534-1541.

16. Fisher NM, Pendergast DR, Fresham GE, et al. Muscle rehabilitation: its effect on muscular and functional performance of patients with knee osteoarthritis. Arch Phys Med Rehabil. 1991;72(6):367-374.

17. Anita E, Hossein B, Mohhamad RH, et al. Isokinetic strength and functional status in knee osteoarthritis. Journal of Physical Therapy Science. 2006;18(2):107-114.

18. Kean CO, Birmingham TB, Garland SJ, et al. Minimal detectable change in quadriceps strength and voluntary muscle Activation in patients with knee osteoarthritis. Arch Phys Med Rehabil. 2010;91(9):1447-1451.

19. Madsen OR, Bliddal H, Egsmose C, et al. Isometric and isokinetic quadriceps strength in knee osteoarthrosis ; inter-relations between quadriceps strength, walking ability, radiology, subchondral bone density and pain. Clin Rheumatol. 1995;14(3):308-314.

20. Diraçoglu D, Baskent A, Yagci I, et al. Isokinetic strength measurements in early knee osteoarthritis. Acta Reumatol Port. 2009;34(1):72-77.

21. Tan J, Balci N, Sepici V, et al. Isokinetic and isometric strength in osteoarthrosis of the knee. A comparative study with healthy women. Am J Phys Med Rehabil. 1995;47(5):364-369.

22. Slemenda C1, Brandt KD, Heilman DK, et al. Quadriceps weakness and osteoarthritis of the knee. Ann Intern Med. 1997;127(2):97-104.

23. Hortobágyi T, Garry J, Holbert D, et al. Aberrations in the control of quadriceps muscle force in patients with knee osteoarthritis. Arthritis Rheum. 2004;51(4):562-569.

24. Glykeria P, Eleftherios K, Nikolaos K, et al. Synergetic and antagonist muscle strength and activity in women with knee osteoarthritis. Journal of Geriatric Physical Therapy. 2014;37(1):17-23.

25. Elsadat SS, Amr Almaz AA. Effect of pain severity on quadriceps isokinetic peak torque in knee osteoarthritis, International Journal of Therapies and Rehabilitation Research. 2014;3(2):17-22.

26. P Rochcongar. Évaluation isocinétique des extenseurs et fléchisseurs du genou en médecine du sport : revue de la littérature. Annales de réadaptation et de médecine physique. 2004;47(6):274-281.

27. Huang MH, Lin YS, Yang RC, et al. A comparaison of various therapeutic exercices on the functional status of patients with knee osteoarthritis. Semin Arthritis Rheum. 2003;23(6):398-406.

28. Huang $\mathrm{MH}$, Yang RC, Lee CL, et al. Preliminary results of integrated therapy for patients with knee osteoarthritis. Arthritis Rheum. 2005;53(6):812-820. 